Document downloaded from:

http://hdl.handle.net/10251/116797

This paper must be cited as:

Buitrago, M.; Adam, JM.; Calderón García, PA.; Moragues, JJ. (2018). Load limiters on shores: Design and experimental research. Engineering Structures. 173:1029-1038. doi:10.1016/j.engstruct.2018.07.063

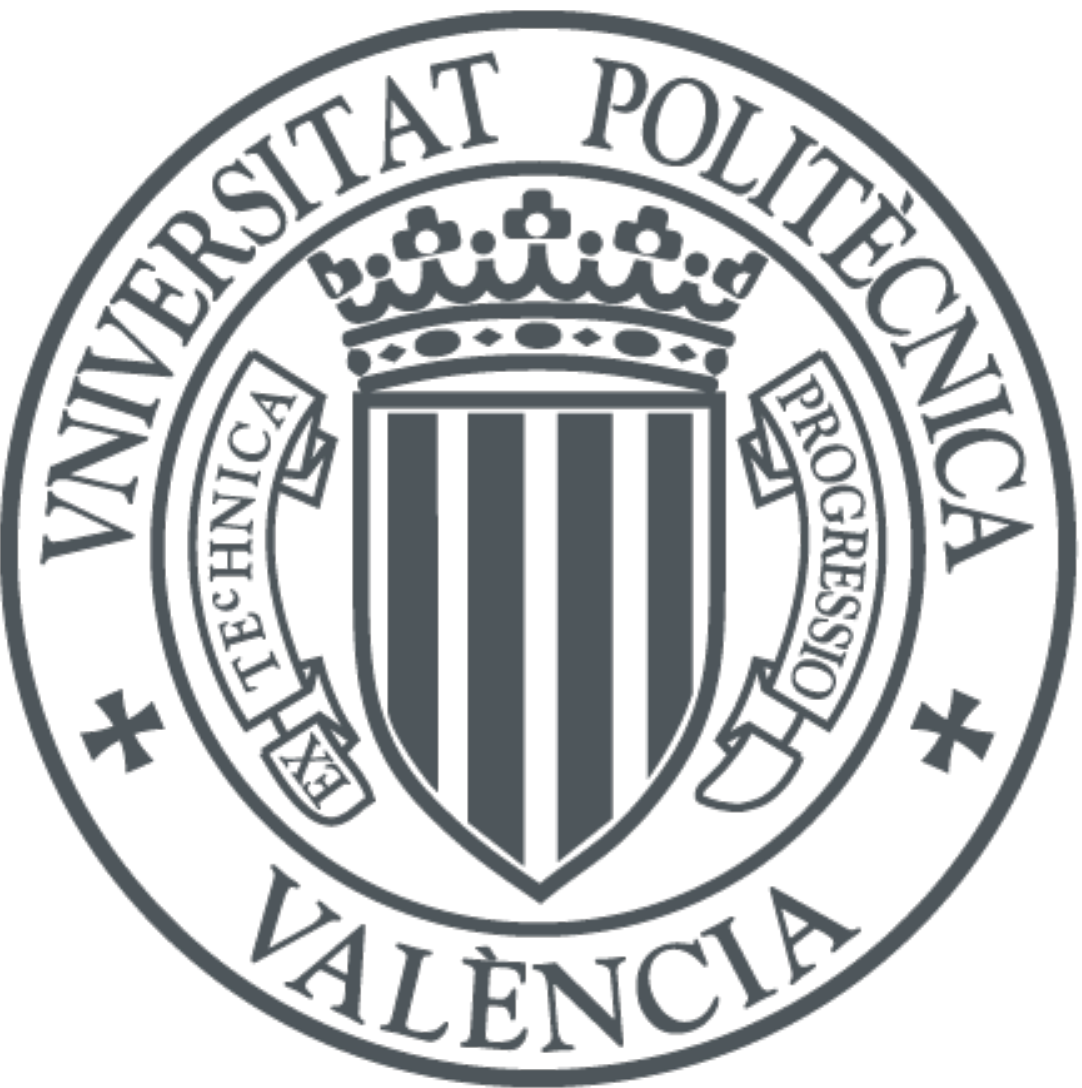

The final publication is available at

http://doi.org/10.1016/j.engstruct.2018.07.063

Copyright Elsevier

Additional Information 


\title{
Load limiters on shores: Design and experimental research
}

\author{
Manuel Buitrago*, Jose M. Adam, Pedro A. Calderón, Juan J. Moragues \\ ICITECH, Universitat Politècnica de València. Camino de Vera s/n, 46022 Valencia, Spain
}

\begin{abstract}
When constructing reinforced concrete building structures, shores are normally used to transmit the loads from freshly poured slabs to lower floors. However, certain problems are involved in this process, including: a) the loads on the shores may be higher than expected, which can lead to the collapse of the shoring system or even of the whole structure, and b) the limited range of shore types in commercial catalogues, which often means that the shores used are oversized. This paper describes the study carried out on the development of a new load-limiter (LL) that can be fitted to shores to improve safety and reduce the cost of constructing building structures. The study shows that combining mechanical and civil engineering fields made it possible to produce a novel device that could revolutionise the shoring techniques at present in use. The method of designing and implementing the LLs involved: a) the design of prototypes by using numerical simulations, b) the use of the design of experiments technique, c) an ambitious experimental campaign in which LL were tested, d) the detailed simulation of the final design, and e) the formulation of a simplified model that considers the behaviour of the shore-LL as a unit. Keywords: Load limiter; Building; DOE; Finite element modelling; Shore.
\end{abstract}

\footnotetext{
* Corresponding author. Tel.: +34 963877562; fax: +34 963877568.

E-mail address: mabuimo1@upv.es (M. Buitrago).
} 


\section{Introduction}

The most frequently used method of constructing RC building structures is by shoring successive levels of floors to transmit the loads of the freshly poured slabs to the lower shored floors [1-3]. The temporary shoring system of each floor is composed of a series of elements: shores (or props), joists and formwork boards [4,5]. A scheme of this system is shown in Fig. 1, together with details of the different components of a type of shore most frequently used at the present time, although other types are available on the market. Shores are fitted in place by adjusting the inner metal tube to the required height by means of a pin. This pin is supported by a ring that transmits the load to an adjustable thread on the upper part of the outer tube. The adjustable thread allows the shore to be accurately adjusted to the exact height required.

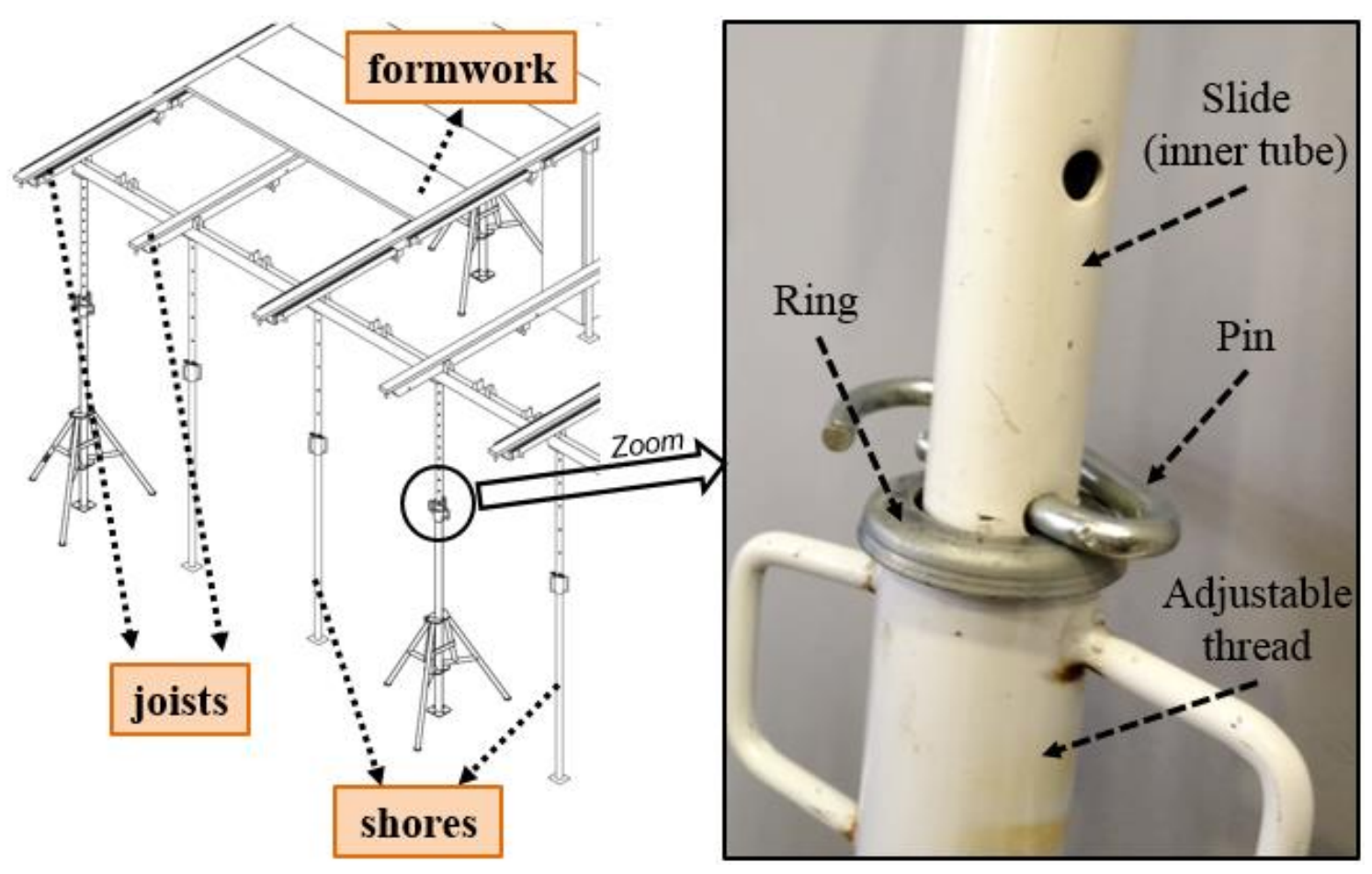

Fig. 1. Sketch of the shoring system and detail of a shore.

Two of the current problems of this shoring system are: a) the shores may be subjected to higher loads than they were designed to withstand, involving the risk of a collapse during construction [6-11], and b) the manufacturers only produce a limited range of shores, which means builders, engineers and architects may be forced to use stronger shores than necessary to ensure structural safety. This paper proposes a novel solution to both these problems in the form of a mechanical device applied in the civil engineering field: the Load Limiter (LL) on shores (Patent number ES2636833). LLs on shores keep the 
loads applied to the shores below their allowable load. Firstly, this device will improve safety during construction while reducing the risk of collapses due to shore failure. Secondly, LLs also mean that lower strength (and cheaper) shores than those initially required can be used, since they limit the shore loads to values below their allowable load, which simplifies on-site handling because lighter shores can be used.

The technical and economic viability of the LLs was confirmed by numerical simulations [12], which achieved: a) improved safety during construction, b) reduced costs, and c) better structural efficiency. The aim of the study was to determine the optimal LL design, production method, together with experimental tests and numerical simulations to check its behaviour. The essential requisites were defined as: a) option of choosing the limit load, b) it had to be re-usable, c) at a reasonable cost, d) with minimum effect on shore stiffness, e) limit and maintain the design limit load of LLs, and f) be easily adaptable to similar types of shores.

The paper is organized as follows: The LL design is described in Section 2 and a brief description of the production process is given in Section 3. Section 4 deals with the different tests carried out and an analysis of the results. Section 5 describes aspects of the numerical simulations, including validation of the models used and a simplified proposal to consider LL behaviour on shores in macro-scale numerical simulations. Finally, Section 6 contains the conclusions drawn from the study.

\section{Design}

Figure 2 shows the desirable stress-strain behaviour of the shore-LL unit, used as the theoretical basis of the LL design.

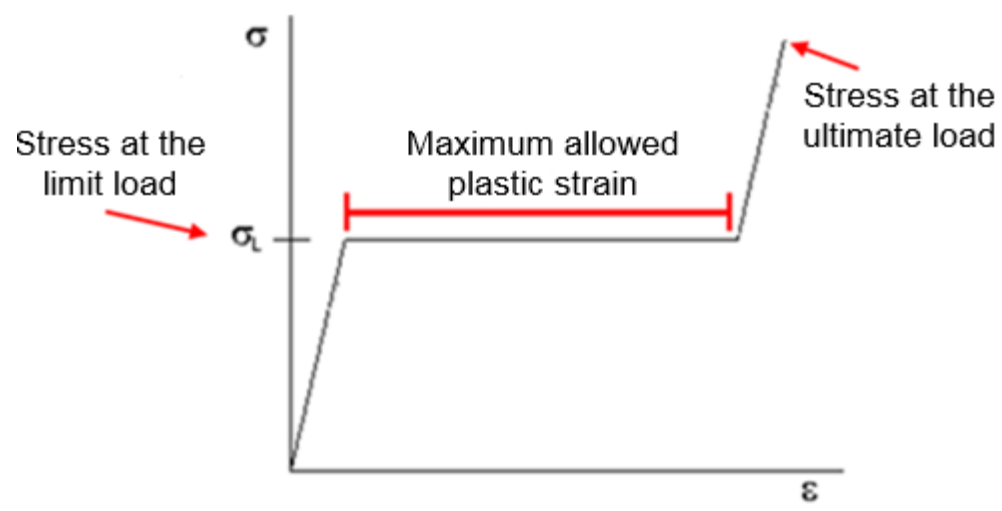

Fig. 2. Theoretical behaviour of load limiters. 
A shore without a LL has a linear elastic behaviour until failure. This failure, by buckling of shore or yielding of the pin, is sudden [13] after which the shore can no longer support the loads it receives, which must be re-distributed through the slab around the neighbouring shores. A shore with an LL must show the same behaviour up to the limit load. However, after the limit load has been reached, and instead of a suddenly breaking and going out of service, the behaviour of a shore with an LL becomes perfectly plastic and keeps the load at its limit load, thus avoiding overloads. The plastic behaviour is limited below the maximum plastic strain or displacement value for safety reasons and to prevent excessive slab cracking. During the plastic behaviour in which the load remains at the limit load, only the excess load hypothetically received by the same shore without a LL must be re-distributed between slabs and the shoring system. After the LL reaches the maximum plastic deformation, the shore can assume a further load up to its ultimate load to make full use of its resistance.

\subsection{First designs}

One of the most difficult aspects was to transfer the theoretical behaviour described above to a LL with a reduced cost. Fig. 3 shows the initially defined ideal position for fitting the LLs to the shores, close to the thread. This position centralises shore operations, which was considered to be a vital aspect to easily install the LL and extend its application. The path of the load arriving at the shore can easily be interrupted between pin and ring to put the LL into position. After a number of iterations, the LL's conceptual design consisted of a frame-type structural system designed to yield at its defined limit load. Its failure mode is controlled by three plastic hinges, one in the centre and two in the upper corners, coinciding with the areas with the smallest cross-section (see Fig. 3b). Each LL is formed of two symmetrically fitted identical elements, as can be seen in the different design stages, which were designed with the help of ANSYS [14] numerical simulations (dealt with in detail in Section 2.2) for a shore taken as reference (see Fig. 1).

Fig. 3c shows the first proposed design, having previously rejected the areas with reduced crosssections to simplify LL manufacture since they are quite small (25 mm long x $10 \mathrm{~mm}$ wide) and the placement of three plastic hinges at the desired points (centre and upper corners) did not require reducing the element's cross-section. The appropriate thickness was chosen to give the LL high bending stiffness so as not to significantly reduce axial stiffness of the shore-LL unit. The improvement of the solution 
shown in Fig. 3c consisted of widening the support surface of the LLs on the rings (see Fig. 3d). The LLs were finally given a circular geometry to fit the shape of the shore and ring, at the same time improving the support conditions (see Fig. 3e). The first results obtained from the ANSYS models [14] were really promising and showed good bending stiffness in the elastic behaviour and plastic behaviour after reaching the limit load. Section 4 gives the results obtained from the experimental tests.

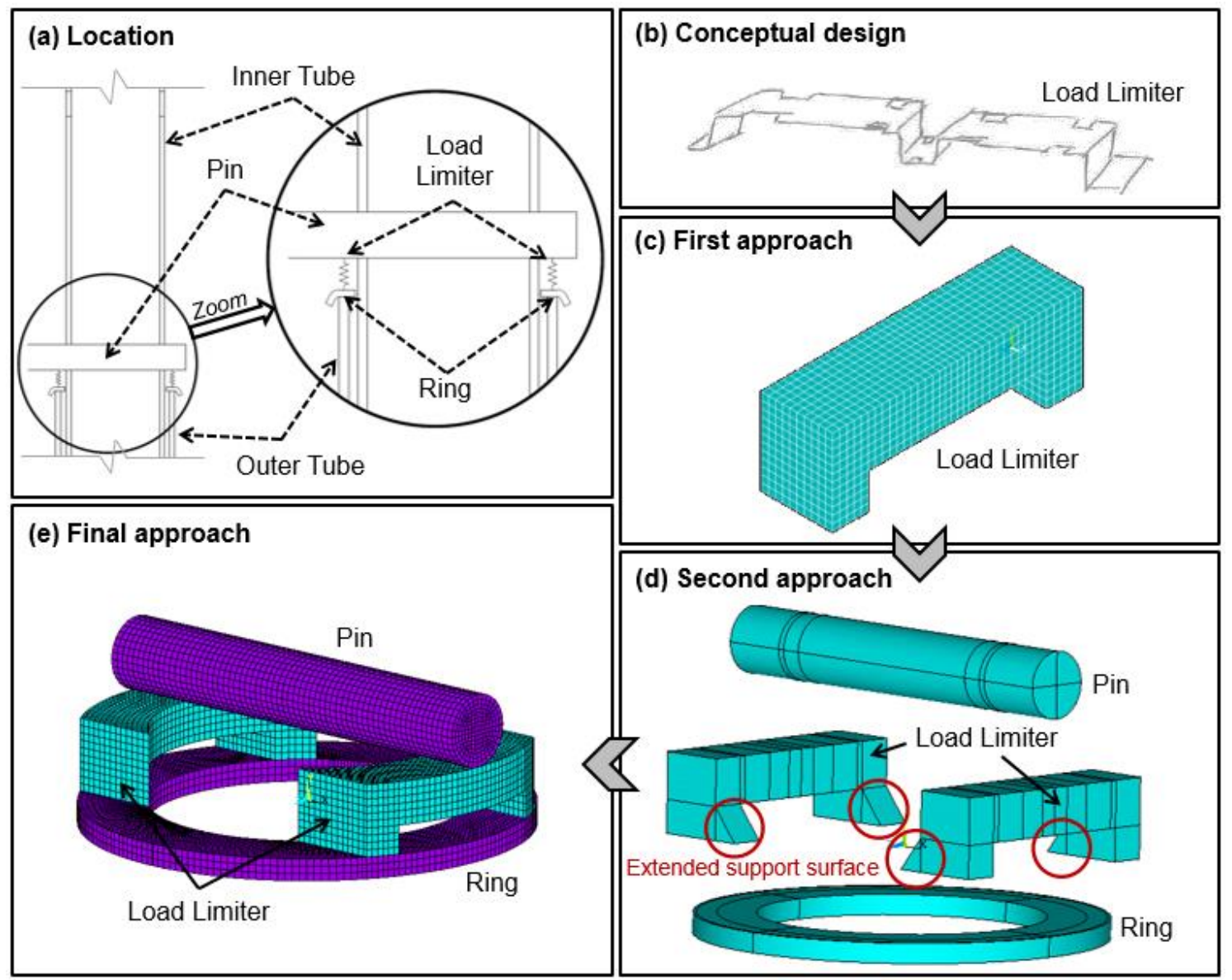

Fig. 3. Stages of the $L L$ design: a) location of $L L$, b) conceptual design, c) first approach, d) second approach and e) final approach.

\subsection{Different solutions}

After analysing the results of the ANSYS simulations [14], a serious limitation was observed in the final design (Fig. 3e); it did not give control over the LL design limit load since the LL support could slide over the ring. A number of solutions were considered (see Fig. 4) aimed at eliminating the slip by including in the LLs: a) tie rods (Fig. 4a), b) confinement (Fig. 4b), or c) confinement based on a stamped ring (Fig. 4c). 


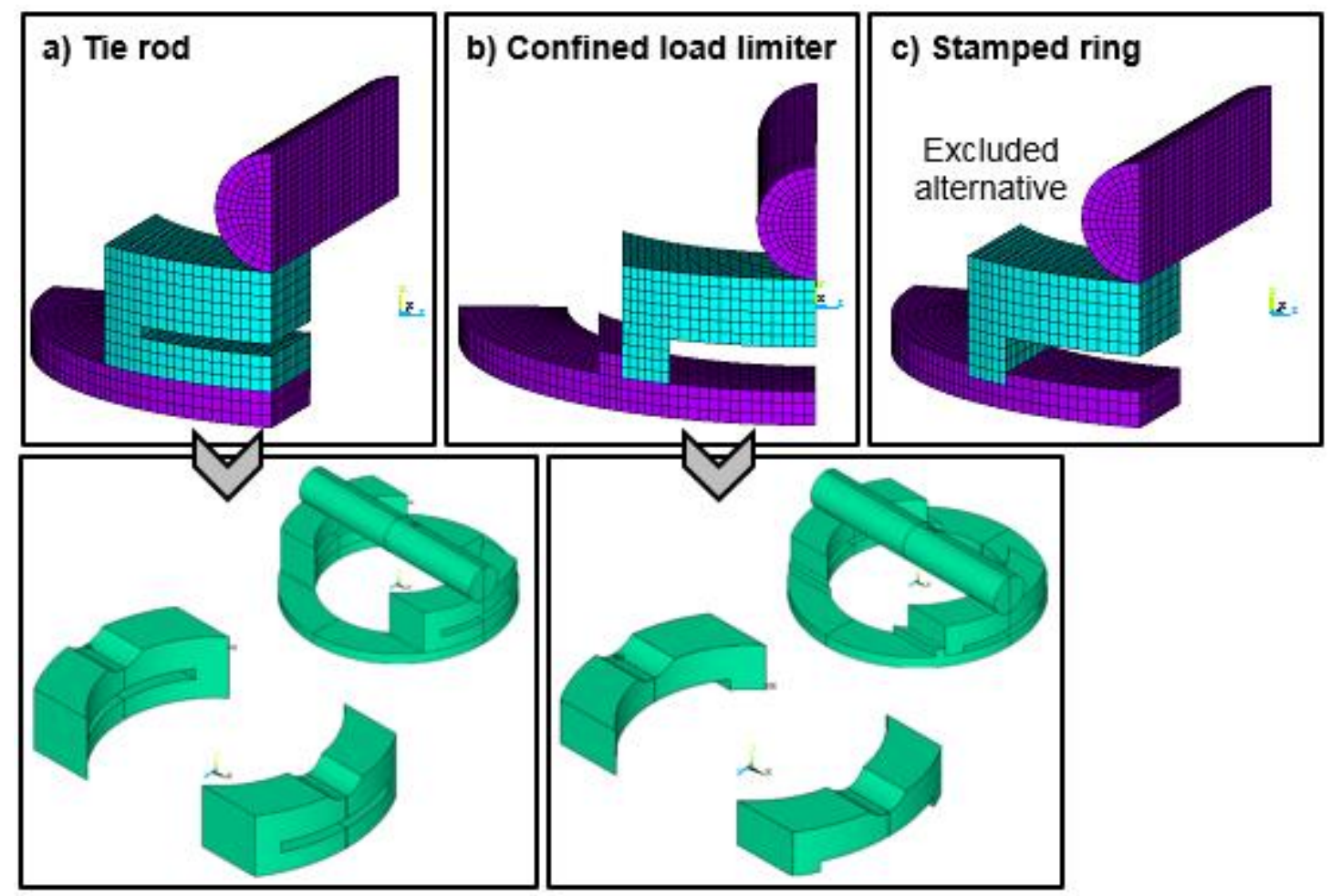

Fig. 4. Different solutions for the design: a) $L L$ with tie rods, b) confined $L L$ and c) stamped ring.

These three solutions were also simulated on ANSYS [14] to see how they worked. SOLID186 [14] type elements were used with 20 nodes and 3 degrees of freedom per node (displacements) to model the ring, LL and pin. In this design phase the steel was considered to have elastic perfectly plastic behaviour with a modulus of elasticity (E) of 210GPa and a small slope for the plastic behaviour (E/10.000). As can be seen in Fig. 4, a quarter of the geometry was modelled due to the double symmetry condition. TARGE170 [14] and CONTA174 [14] type elements were used, with 4 nodes and 3 degrees of freedom per node, for the two contact surfaces, pin-LL and LL-ring. Both elements were defined for the same surface, using the TARGE170 element for the lower part (LL or ring respectively) and the CONTA174 element for the upper part (pin or LL respectively). Slipping was allowed on the contact surfaces with a friction coefficient between both steel elements of 0.6 , which is between the values found in the scientific literature $[15,16]$. Regarding the boundary conditions, horizontal displacements were not allowed on the horizontal plane of the ring and vertical displacements were restricted on nodes over the thread where the ring is supported. The results obtained showed that all three solutions had good behaviour and avoided LL slippage on the ring. 
The third solution shown in Fig. 4 was rejected out of hand due to precision requirements in its production process. A pin-mark was included in the first two, as can be seen in the lower part of Fig. 4.

\subsection{Design of experiments and selection of $L L$ for manufacture}

The final design of the chosen solutions (LL with tie rods and confined LL) was obtained through the design of experiments (DOE) technique [17-22] in order to achieve all the possible solutions from the calculations of a small number of models. The considered variables for the different designs (LL with tie rod and confined LL) were: a) thickness of the upper part of LL, between $4 \mathrm{~mm}$ and 8mm; and b) thickness of the lateral parts of LL, between $2 \mathrm{~mm}$ and $6 \mathrm{~mm}$. Tie rod thickness, between $2 \mathrm{~mm}$ and $4 \mathrm{~mm}$, and height (maximum plastic displacement), between $1 \mathrm{~mm}$ and $2 \mathrm{~mm}$, were considered as variables for LL with tie rods and confined LL, respectively. Height was only considered in the confined LL design to study its influence on the limit load and limit the number of processed models. The considered height was constant with a value of $2.0 \mathrm{~mm}$ in the LL with tie rod design. The remaining parameters such as the dimensions and steel grade (yielding point at 275MPa) were given constant values. Tables 1 and 2 show the 16 models proposed by the DOE [23] for each design. The DOE used the response surface method with central composite design ( $\left.2^{\wedge} 3+\operatorname{star}[23]\right)$, rotatable, with two randomly placed star points and three levels for each factor. The analysis considered simple interactions in a quadratic model. Tables 1 and 2 show the limit load obtained by numerical simulation [14] of the 32 models proposed by the DOE [23]. The response model was then fitted with an r-squared of 99.9\%. The design curves of the LLs of each design can be seen in Fig. 5 depending on the adopted variables and desired limit load.

The first lot of LLs, 4 with tie rods and 4 confined, were made with the following characteristics:

- L01-A: LL with $3.0 \mathrm{~mm}$ thick of tie rods, an expected limit load of $14 \mathrm{kN}, 4.0 \mathrm{~mm}$ thick lateral parts and $5.3 \mathrm{~mm}$ thick upper part.

- L01-B: Confined LL with an expected limit load of $14 \mathrm{kN}, 4.0 \mathrm{~mm}$ thick lateral parts, $5.5 \mathrm{~mm}$ thick upper part and $2.0 \mathrm{~mm}$ in height. 
Table 1. Design of experiments and results of load limiters with tie rods.

\begin{tabular}{ccccc}
\hline Model & $\begin{array}{c}\text { Thickness of the } \\
\text { upper part }[\mathrm{mm}]\end{array}$ & $\begin{array}{c}\text { Thickness of the } \\
\text { lateral parts }[\mathrm{mm}]\end{array}$ & $\begin{array}{c}\text { Tie rod thickness } \\
{[\mathrm{mm}]}\end{array}$ & $\begin{array}{c}\text { Limit load } \\
{[\mathrm{kN}]}\end{array}$ \\
\hline 01 & 8.0 & 2.0 & 2.0 & 18.5 \\
02 & 4.0 & 2.0 & 2.0 & 6.8 \\
03 & 9.7 & 4.0 & 3.0 & 30.0 \\
04 & 3.0 & 4.0 & 3.0 & 6.0 \\
05 & 6.0 & 4.0 & 1.3 & 15.8 \\
06 & 4.0 & 6.0 & 4.0 & 10.3 \\
07 & 4.0 & 6.0 & 2.0 & 9.8 \\
08 & 6.0 & 4.0 & 3.0 & 17.0 \\
09 & 4.0 & 2.0 & 4.0 & 6.8 \\
10 & 8.0 & 2.0 & 4.0 & 18.5 \\
11 & 8.0 & 6.0 & 2.0 & 25.5 \\
12 & 8.0 & 6.0 & 4.0 & 28.5 \\
13 & 6.0 & 1.0 & 3.0 & 10.0 \\
14 & 6.0 & 6.0 & 3.0 & 19.5 \\
15 & 6.0 & 2.0 & 3.0 & 12.8 \\
16 & 6.0 & 4.0 & 4.7 & 17.0 \\
\hline
\end{tabular}

Table 2. Design of experiments and results of confined load limiters.

\begin{tabular}{ccccc}
\hline Model & $\begin{array}{c}\text { Thickness of the } \\
\text { upper part [mm] }\end{array}$ & $\begin{array}{c}\text { Thickness of the } \\
\text { lateral parts }[\mathrm{mm}]\end{array}$ & $\begin{array}{c}\text { Height } \\
{[\mathrm{mm}]}\end{array}$ & $\begin{array}{c}\text { Limit load } \\
{[\mathrm{kN}]}\end{array}$ \\
\hline 01 & 6.0 & 4.0 & 2.3 & 16.5 \\
02 & 8.0 & 6.0 & 2.0 & 25.8 \\
03 & 8.0 & 6.0 & 1.0 & 25.0 \\
04 & 6.0 & 6.0 & 1.5 & 16.5 \\
05 & 6.0 & 4.0 & 0.7 & 15.0 \\
06 & 8.0 & 2.0 & 1.0 & 22.5 \\
07 & 4.0 & 2.0 & 1.0 & 6.8 \\
08 & 4.0 & 6.0 & 2.0 & 9.0 \\
09 & 6.0 & 1.0 & 1.5 & 12.0 \\
10 & 9.4 & 4.0 & 1.5 & 31.5 \\
11 & 4.0 & 6.0 & 1.0 & 8.0 \\
12 & 8.0 & 2.0 & 2.0 & 22.8 \\
13 & 6.0 & 4.0 & 1.5 & 15.5 \\
14 & 3.0 & 4.0 & 1.5 & 5.0 \\
15 & 6.0 & 2.0 & 1.5 & 13.8 \\
16 & 4.0 & 2.0 & 2.0 & 6.9 \\
\hline
\end{tabular}


(a)

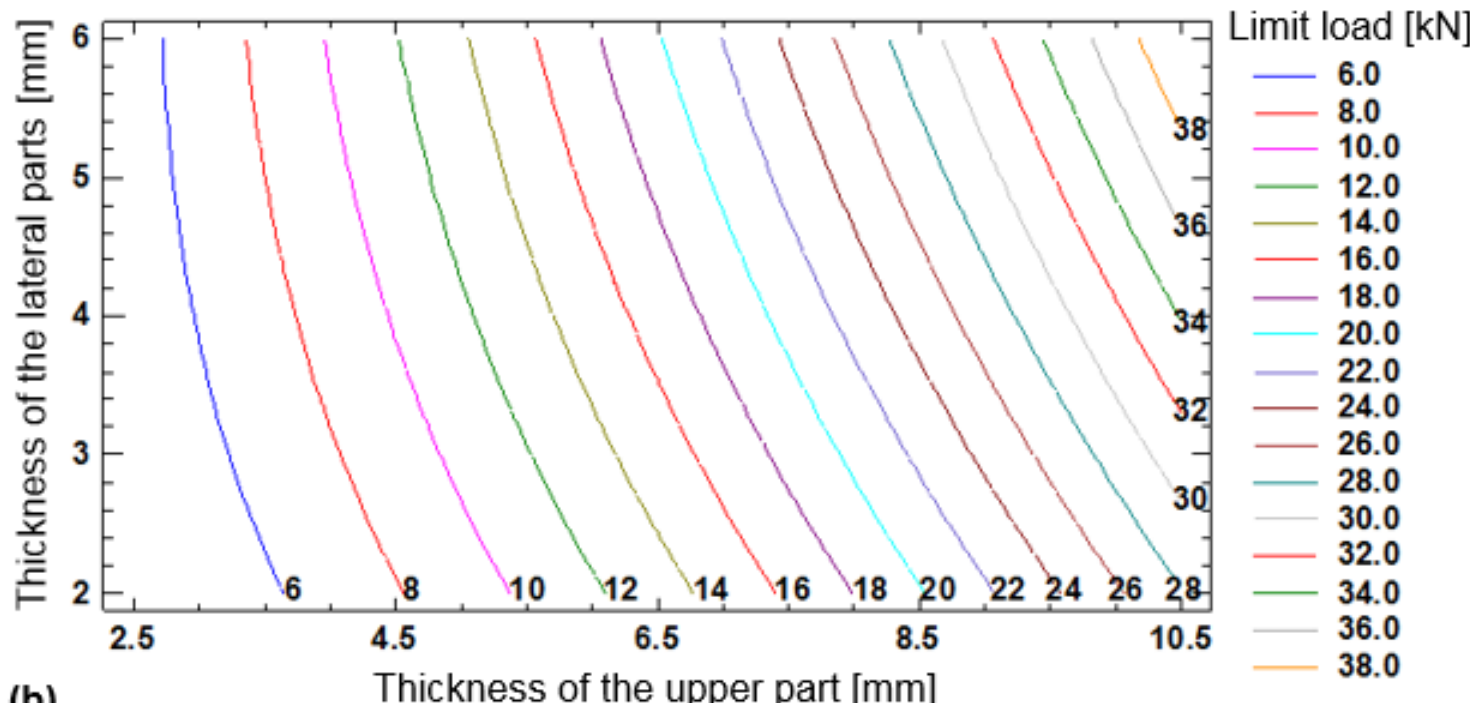

(b)

Thickness of the upper part [mm]

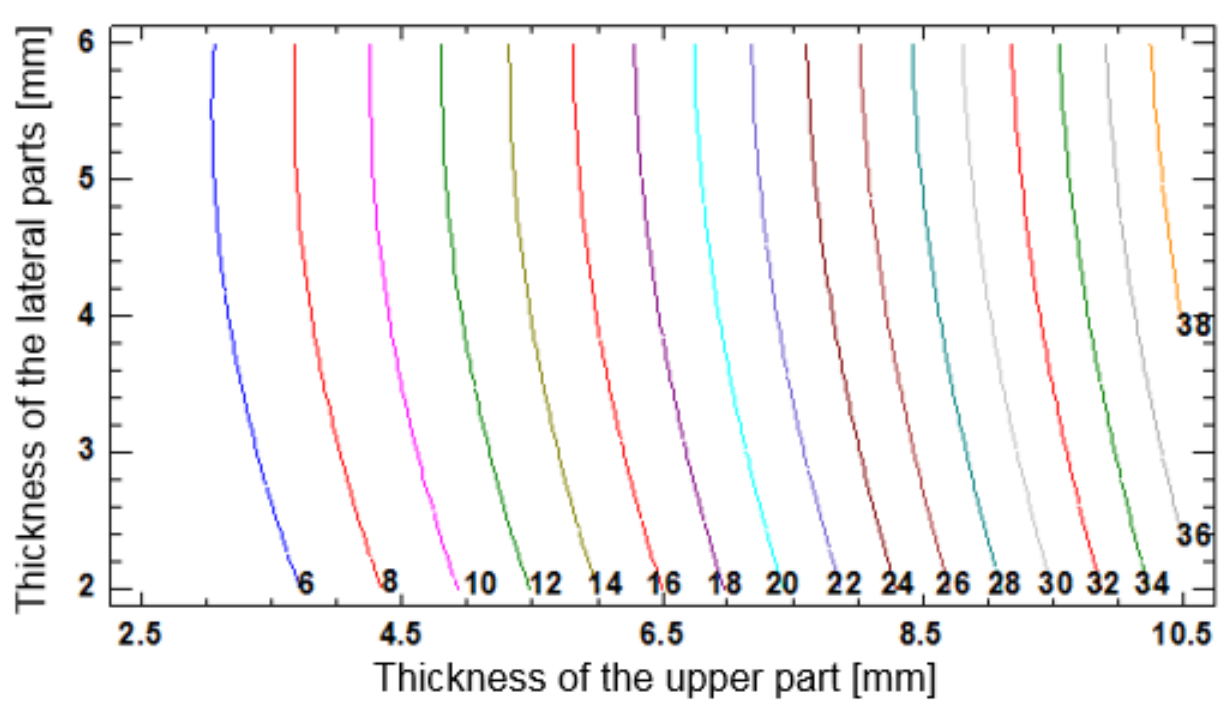

Limit load $[\mathrm{kN}]$

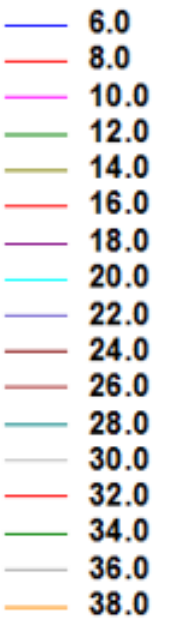

Fig. 5. Design curves for the solutions: (a) load limiters with $3 \mathrm{~mm}$ tie rods and (b) confined load limiters with $2 \mathrm{~mm}$ height.

\section{Production}

The LLs were machine produced. Much of their geometry was defined by numerical control after preparing the surfaces of the raw material (S275 JR steel) (see Fig. 6a). Their definitive geometry was defined manually. Figs. $6 \mathrm{~b}$ and $6 \mathrm{c}$ show the final result of the LL with tie rods and confined LL, respectively. One of the former was fitted with a wire between the two LL elements with the aim of being installed at the same time and checking the correct behaviour of this prototype. Fig. $6 \mathrm{~b}$ shows the LL with tie rods fitted to a shore. A detail of a ring modified to confine a confined LL can be seen in Fig. 6c. 
(a) Manufacturing process

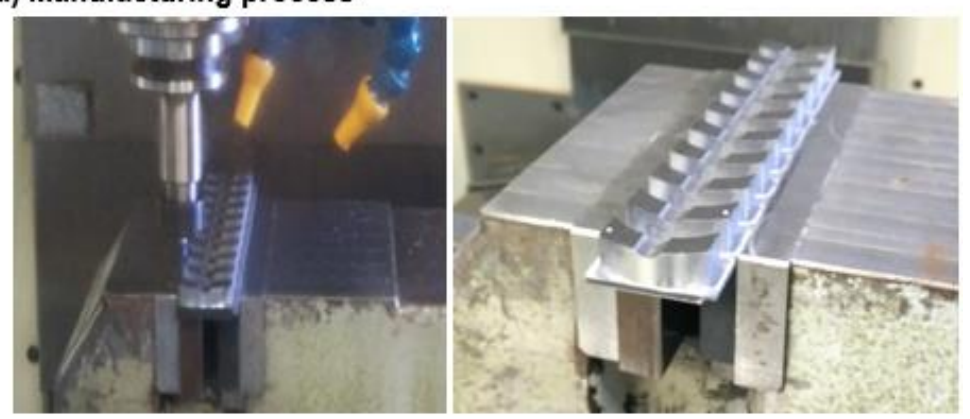

(b) Load limiter with tie rods

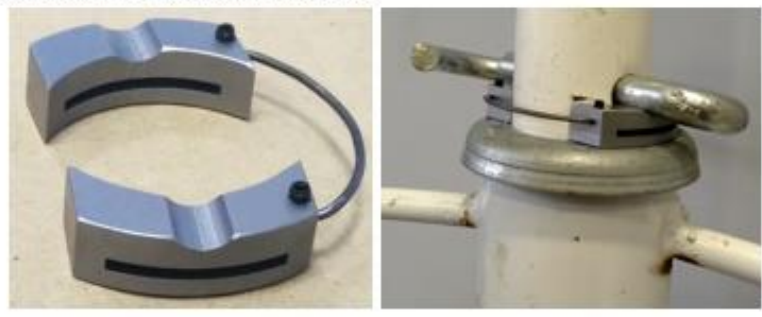

(c) Confined load limiter

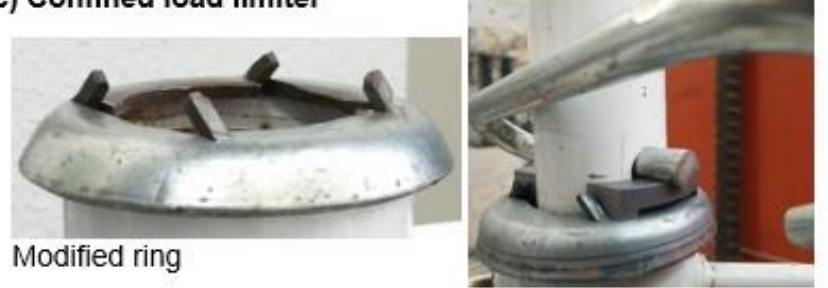

Fig. 6. Production of LL: a) manufacturing process, b) LL with tie rods and c) confined LL.

\section{Test}

The LLs were tested at the ICITECH laboratories of the Universitat Politècnica de València in two different situations. They were first tested on shores in normal working conditions and then individually in order to determine their behaviour away from the influence of uncontrollable factors when they are installed on shores. The configuration can be seen in Fig. 7.

Fig. 7a shows the configuration of tests of shores fitted with LLs. A 50kN maximum capacity hydraulic jack and a load cell placed between shore and the hydraulic jack were used. The load cell was used solely to confirm the correct measurement of the load from the mean deformation of three strain gauges fitted symmetrically to around the shore perimeter and separated by $120^{\circ}$, as has been validated in numerous studies $[13,24,25]$. A device for displacement control had a chain that descends as the shore is compressed to control displacement speed and thus correctly records the LL's plastic behaviour. Two LVDTs were used to record displacements during the tests. A semi-spherical support was placed under the shore to reduce the eccentricity of the axial load, as recommended by EN 1065 [26]. 
The test configuration of the isolated LLs can be seen in Fig. 7b. The LLs were supported on the ring and thread to simulate their actual form of support. The load was applied by a cylinder with the same diameter as the pin of the shore used in the tests $(10 \mathrm{~mm})$. An LVDT and a load cell were also used to record the results. Fig. 8 contains a series of views taken during the tests on the shores fitted with LLs (Fig. 8a) and isolated LLs (Fig. 8b) for LLs with tie rods and confined LLs.

\section{(a) Tests of LLs on shores}

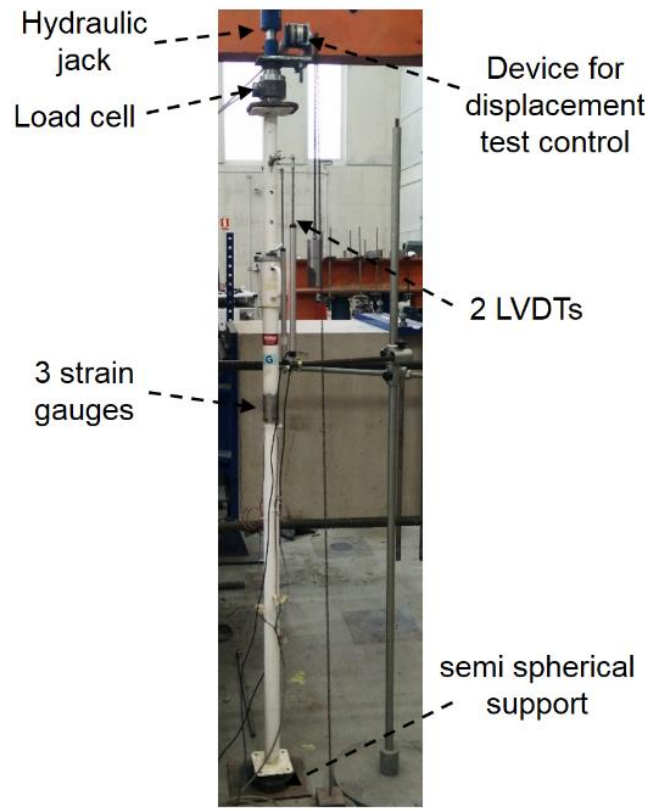

(b) Tests of isolated LLs

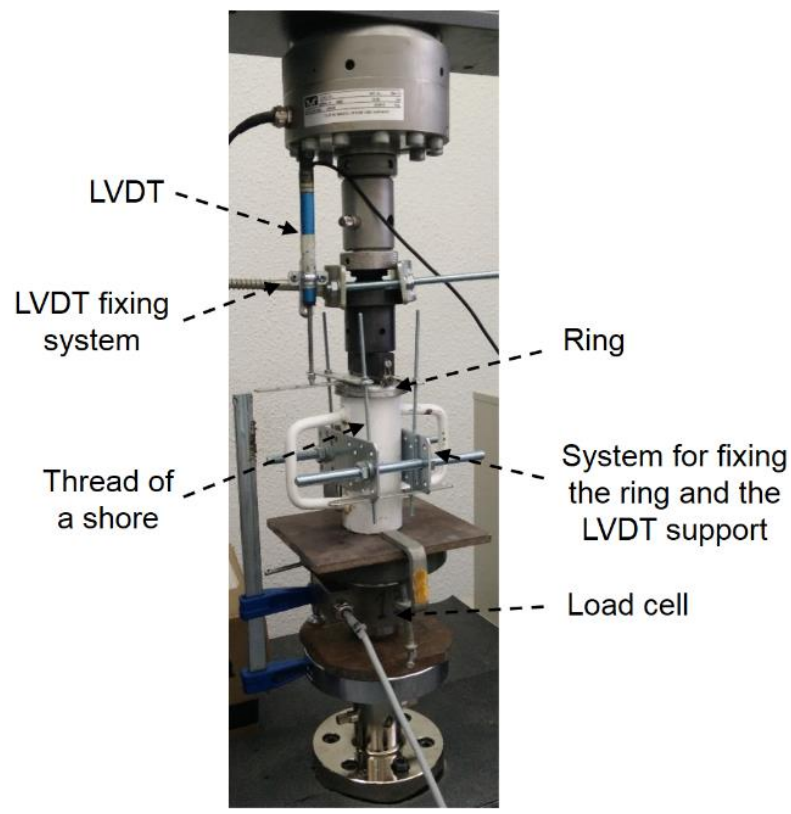

Fig. 7. Tests setups.

\section{(a) Tests of LLs on shores}

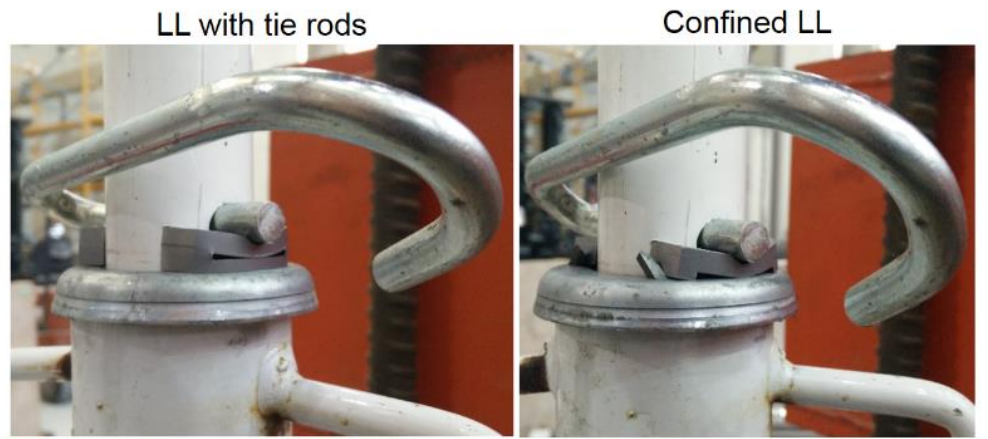

(b) Tests of isolated LLs

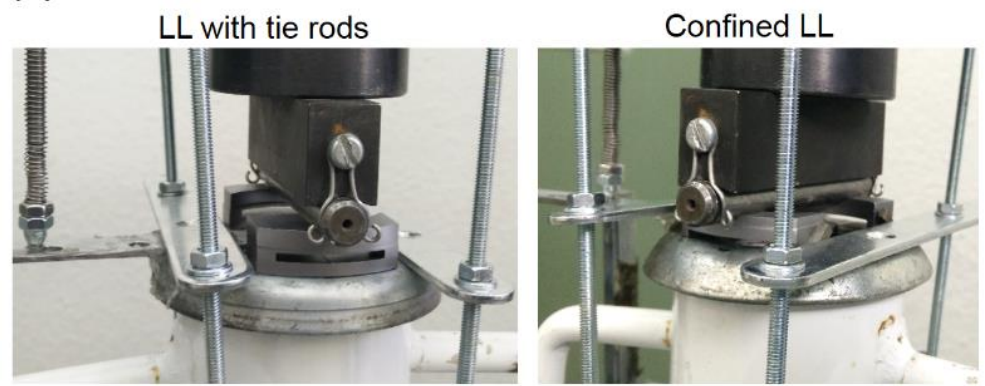

Fig. 8. Tests of LLs on shores and isolated LLs. 


\subsection{Lot 1}

The steel grade used for the LLs was one of the parameters that must be controlled. The quality control of the steel used in the first lot was carried out in accordance with EN-ISO 6892 [27] (see Fig. 9). The steel was found to have a yielding point of 355MPa, so that the expected limit load would be significantly higher than the $14 \mathrm{kN}$ defined in the design phase.
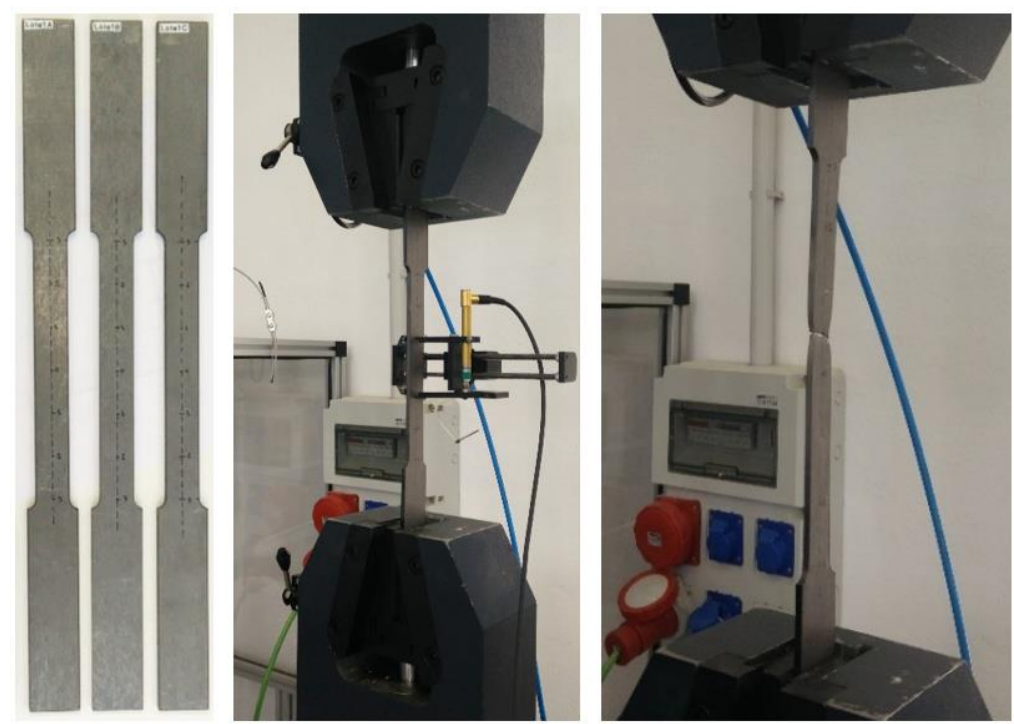

Fig. 9. Steel characterization test setup.

Fig. 10 gives the results of the tests on the shores. They show that the different limit loads of the LLs with tie rods remains at $18 \mathrm{kN}$, while those of the confined LLs vary widely between $9 \mathrm{kN}$ and $12 \mathrm{kN}$. Both designs also had large differences in initial stiffness and maximum LL plastic displacement, although these results could have been influenced by the test conditions.

(a)

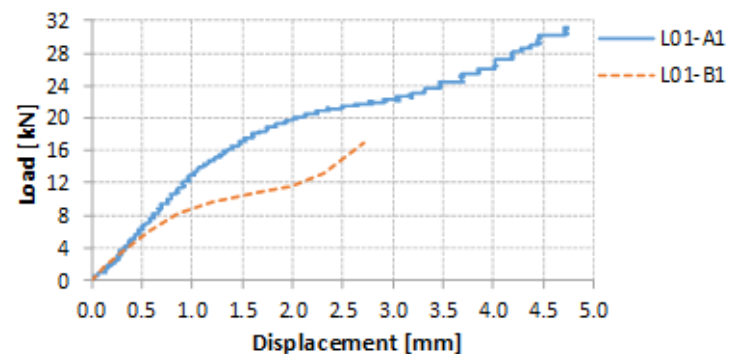

(b)

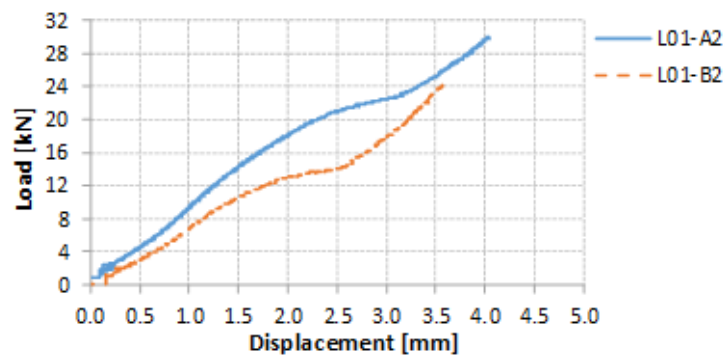

Fig. 10. Tests on shores for LLs with tie rods (L01-A1, L01-A2) and confined LLs (L01-B1, L01-B2).

Fig. 11 gives the results of the tests on the isolated LLs. The previous results in which the LLs with tie rods (design A) have a higher limit load than the confined LLs (design B) were confirmed, even though both were designed to have the same limit load. 
(a)

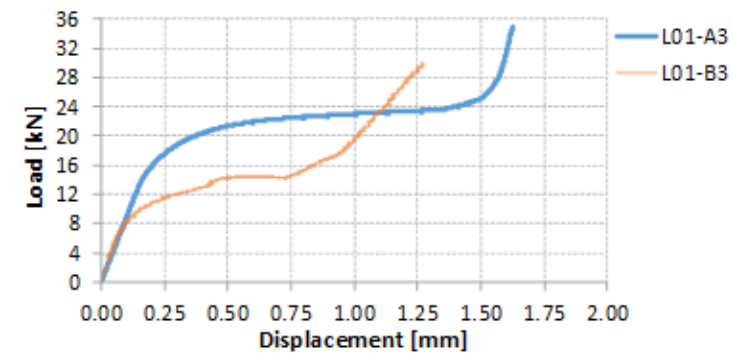

(b)

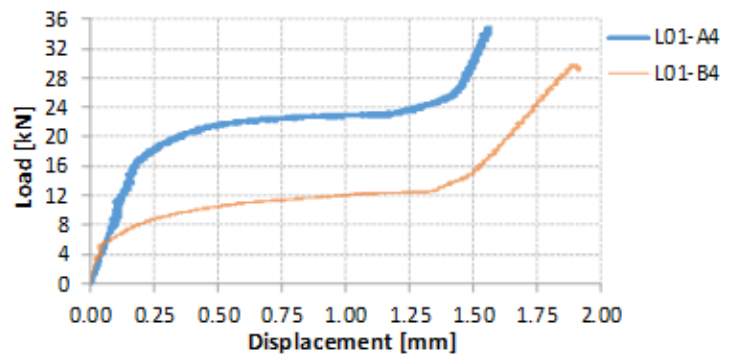

Fig. 11. Tests of isolated LLs with tie rods (L01-A3 and L01-A4) and isolated confined LLs (L01-B3 and L01-B4).

It can also be seen in Fig. 11 that the different confined LLs (design B) show significant differences as to the limit load and maximum plastic displacement obtained, both being unacceptable behaviour in shores. The confinement conditions of the ring were not effective, showing different behaviour in each of the elements of the same LL and permitting the partial slippage of the LL on the ring. On the other hand, the LLs with tie rods (design A) had a similar limit load and maximum plastic displacement in all the tests, and also the high bending stiffness required for LLs. The maximum displacement values were around $1.50 \mathrm{~mm}$, although the design and production value was $2.0 \mathrm{~mm}$. The effective maximum displacement during the test was lower for a number of reasons:

- The LLs presented a bi-directional bending component.

- Design A, with a similar behaviour of a frame, showed a slight raising of the central section of the tie rod.

- In design B there was partial slippage between LL and ring that varied from test to test.

In view of the results obtained, the consistent experimental behaviour of the individual LLs with tie rods (design A) complies with the initial requirements. However, the confined LLs (design B) did not function correctly and the results were widely dispersed and so was discarded. The study thus continued with a second lot only consisting of LLs with tie rods.

\subsection{Lot 2}

Lot 2 consisted of 16 LLs with tie rods (design A) on two levels of limit load ( 8 for the first level, L1; and 8 for the second level, L2), steel with a yielding point of 275MPa and with the following values of the variables: 
- L02-AL1: LL with 3.0mm thick tie rods, $4.0 \mathrm{~mm}$ thick lateral parts and 5.3mm thick upper part (same geometry as first lot).

- L02-AL2: LL with $3.0 \mathrm{~mm}$ thick tie rods, $4.0 \mathrm{~mm}$ thick lateral parts and $6.3 \mathrm{~mm}$ thick upper part (with higher load limit).

In each group of eight LLs, four were tested under monotonic loads, both for isolated (2) and fitted to shores (2), while four were tested under repetitive loads with load-unload cycles to verify possible reutilisation of the LLs that did not reach a certain plastic displacement. The test plan under repetitive loads was different and defined from the load-displacement curve of the LLs tested under monotonic loads. Table 3 shows the Identification (ID and code), test type and loading of the different tests. The number of load-unload repetitions is later defined for each test.

Steel was tested before the tests by the same method used to test Lot 1 (see Fig. 9). Fig. 12a gives the results of two specimens in which the steel showed a yielding point of $275 \mathrm{MPa}$, so that the expected load limit was $14 \mathrm{kN}$ (see Fig. 5a).

Given the similarity of the results and conclusions obtained from the two load levels tested (L1 and L2), the results of L1 only are given. Fig. 12b gives the results of the tests under monotonic loads on the shore-LL unit and Fig. 13a those of the isolated LL.

The consistent behaviour of the different LLs fitted to shores can be seen in Fig. 12b, also the drastic drop in shore stiffness after reaching its limit load of $14 \mathrm{kN}$.

Table 3. Performed tests for each level of limit load (L02-AL1 and L02-AL2).

\begin{tabular}{|c|c|c|c|c|c|c|c|c|}
\hline \multirow[b]{2}{*}{ ID } & \multirow[b]{2}{*}{ Test type } & \multirow[b]{2}{*}{ Loading } & \multirow[b]{2}{*}{ Code } & \multicolumn{5}{|c|}{ Number of load-unload repetitions ${ }^{*}$} \\
\hline & & & & $\begin{array}{c}\text { Point } \\
1\end{array}$ & $\begin{array}{c}\text { Point } \\
2\end{array}$ & $\begin{array}{c}\text { Point } \\
3\end{array}$ & $\begin{array}{c}\text { Point } \\
4\end{array}$ & $\begin{array}{c}\text { Point } \\
6\end{array}$ \\
\hline 1 & Isolated & Monotonic & L02-ALX-1 & 3 & --- & --- & --- & 1 \\
\hline 2 & Isolated & Monotonic & L02-ALX-2 & 3 & --- & --- & --- & 1 \\
\hline 3 & Isolated & Cyclic & L02-ALX-3 & 3 & --- & 190 & --- & 1 \\
\hline 4 & Isolated & Cyclic & L02-ALX-4 & 3 & --- & --- & 190 & 1 \\
\hline 5 & Isolated & Cyclic & L02-ALX-5 & 3 & 20 & 20 & 30 & 1 \\
\hline 6 & Isolated & Cyclic & L02-ALX-6 & 3 & 20 & $\begin{array}{c}20+ \\
120\end{array}$ & 30 & 1 \\
\hline 7 & Shore & Monotonic & L02-ALX-7 & 3 & --- & --- & --- & 1 \\
\hline 8 & Shore & Monotonic & L02-ALX-8 & 3 & --- & --- & --- & 1 \\
\hline
\end{tabular}


(a)

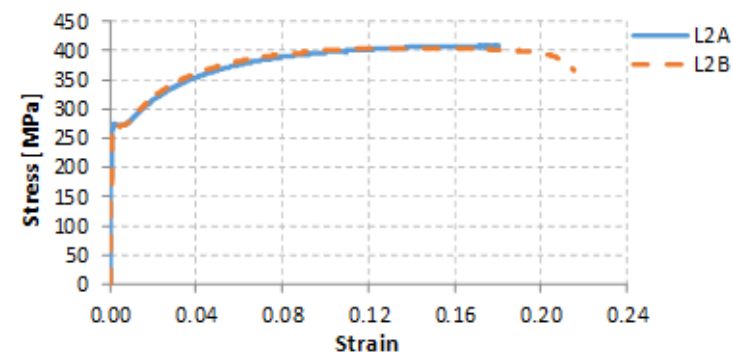

(b)

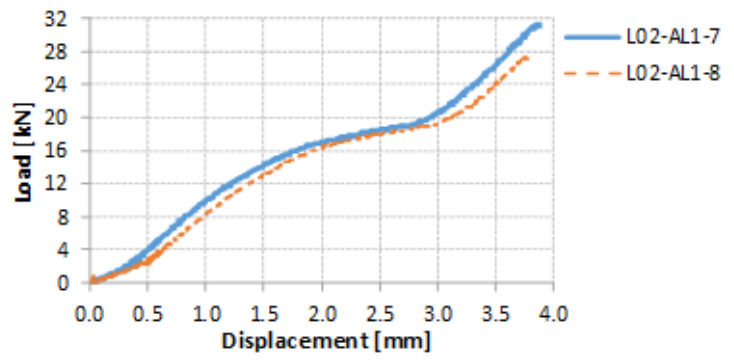

Fig. 12. (a) Steel characterization and (b) tests of LLs on shores (L02-AL1-7, L02-AL1-8).

The results shown in Fig. 13a also confirm the good behaviour of the LLs with tie rods, with: a) very high initial stiffness and negligible effect on shore stiffness, b) a limit load similar to expected limit load, c) conservation of the load limit during the plastic behaviour, d) limited plastic displacement after which the shore again becomes loaded, and e) constant results of the different tests.

The tests applying repetitive loads (load-unload cycles) were defined with reference to Fig. 13b, showing the different points on the load-displacement curve to which the LLs were subjected (see also Table 3):

1. Reduced load for the first repetitions. This load level was used to set up all the test system so as to start all the tests under the same conditions.

2. Point defined on the elastic behaviour to check LLs just before reaching limit load.

3. Limit load point, defined as the point at which the slope (or the stiffness) is the mean of the initial slope (elastic segment) and final slope (plastic segment).

4. Mid point of plastic segment between Points 3 and 5.

5. End of plastic segment and start of second load segment.

6. Maximum load reached in tests.

(a)

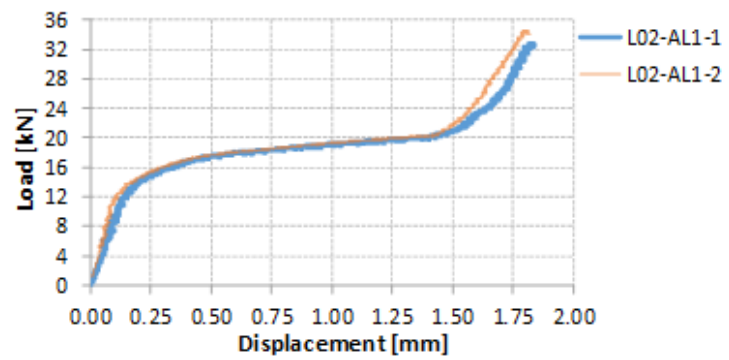

(b)

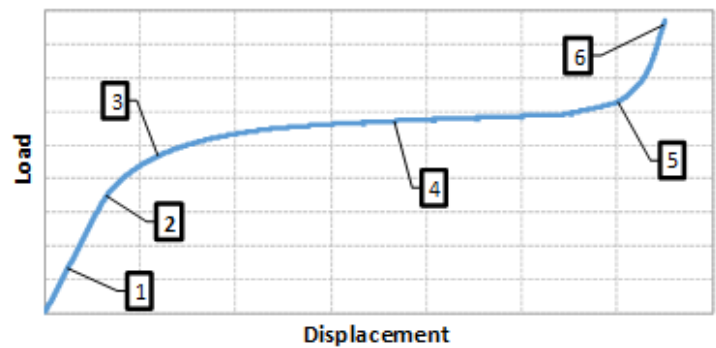

Fig. 13. (a) Tests of isolated LLs (L02-AL1-1, L02-AL1-2) and (b) points on the load-displacement curve for the definition of the cyclic tests. 
Table 3 defines the number of load-unload repetitions at each point defined in Fig. 13b. Besides the initial load with three repetitions (used in all tests, including monotonic), two tests were performed with 190 repetitions at a certain point on the LL behaviour curve (L02-ALX-3 and L02-ALX-4), with two others considering the accumulated damage and repetitive loads at different points on the curve (L02ALX-5 and L02-ALX-6). Note that in test L02-ALX-6, in which after the pre-load, 20 repetitions were performed at Point 2, 20 at Point 3,30 at Point 4, and 120 more at the limit load after having reached half of the maximum plastic displacement. Fig. 14 gives the results of the tests under repetitive loads of the LLs at the first limit load level (L1).

Fig. 14a gives the result of test L02-AL1-3. As can be seen, at the limit load level there has already been a slight plastic displacement of the load limiters. It is also quite obvious that with 190 repetitions the LLs can be re-used even after undergoing limit load values. Their behaviour after 190 load-unload cycles is practically identical to the initial behaviour.

Similar conclusions were obtained from L02-AL1-4 (see Fig. 14b) although the damage accumulated at point 4 is evident. There was an additional plastic displacement each time point 4 was reached (updated value of limit load). In these cases, when the LLs have reached half the maximum plastic displacement their safety level decreases and should be replaced.

(a)

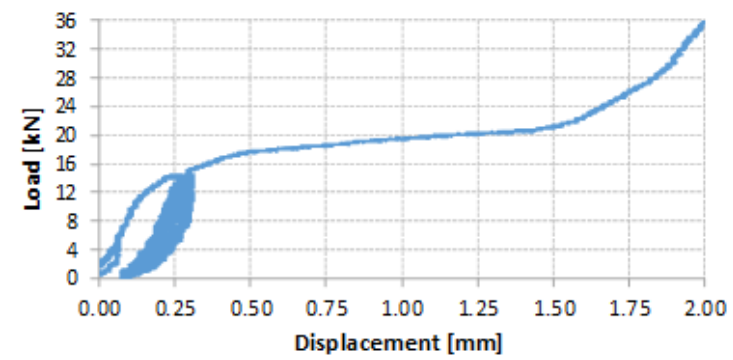

(c)

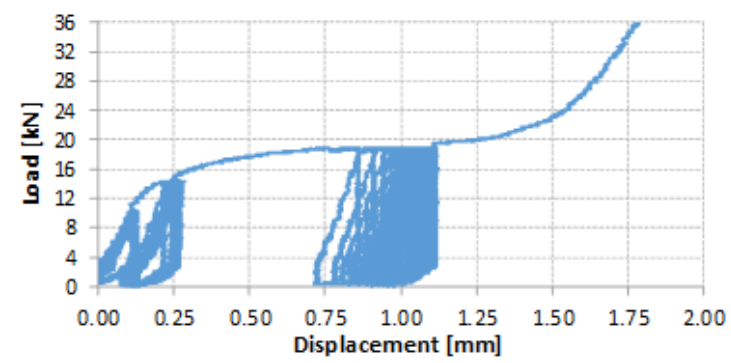

(b)

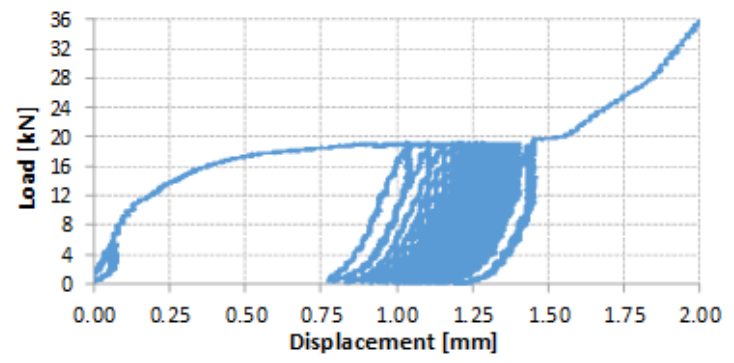

(d)

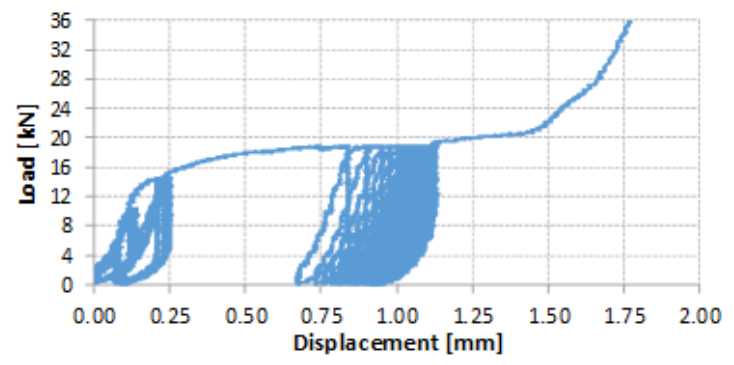

Fig. 14. Results of tests of isolated LLs with cyclic loading: (a) L02-AL1-3, (b) L02-AL1-4, (c) L02-AL1-5, and (d) L02-AL1-6. 
Fig. 14c shows the results of L02-AL1-5. Here again it was shown that it would have been possible to use the LLs again in spite of the damage they suffered at different levels. Similar conclusions were obtained as for L02-AL1-4 on reaching or passing the halfway point of maximum plastic displacement (point 4).

Finally, in the most demanding test carried out (L02-AL1-6) (see Fig. 14d) similar conclusions were obtained. Even after reaching half the maximum plastic displacement, if the LLs do not again pass their limit load, their safety reserve is still able to prevent loads higher than the limit load, although, as commented above, their replacement is recommended.

\section{Simulation}

The first numerical models included simplified theoretical steel behaviour, as defined in Section 2.2. Here the simulation of the definitive LL design is described with the real steel behaviour obtained from the tests described in Section 4.2 (Fig. 12a).

Fig. 15a gives the results of simulation (L02-AL1) as compared to those of test (L02-AL1-1). It can be seen that the numerical models stay close to the actual behaviour, showing that the method used is $100 \%$ valid for predicting the behaviour of any new LL designs.

(a)

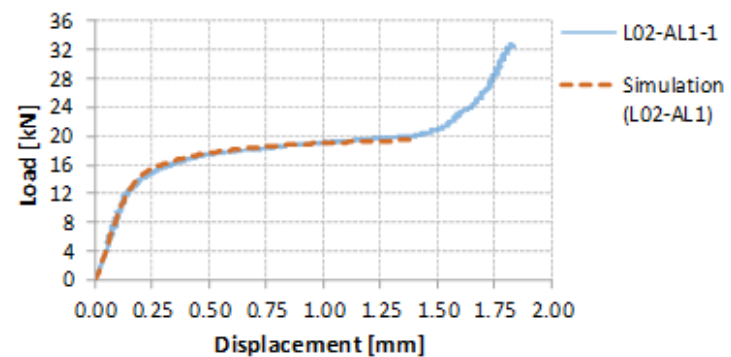

(b)

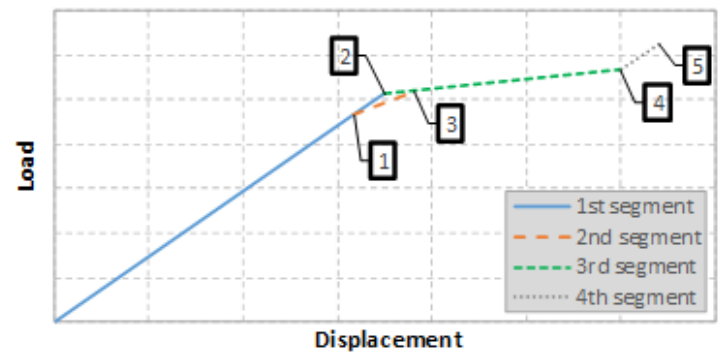

Fig. 15. (a) Comparison between simulated and experimental results and (b) simplified LL on shore behaviour for macro-scale models.

The method used in this study to simulate LLs on shores has a high computational cost which only makes sense for micro-scale analyses, i.e. on the behaviour of a single shore, such as those described in this paper. For macro-scale models, e.g. to simulate the construction of building structures with LLs attached to the shores, simpler shore-LL behavioural models should be used. Fig. 15b contains a proposal for one such model fitted to experimental data and defined mainly by 4 curve segments: 
- Point 2: Defined as the LL's limit load $\left(\mathrm{q}_{\mathrm{y}}\right)$ with stiffness of E'A/L (slope in the first segment) equal to shore stiffness but with a small reduction of the elasticity modulus (E') from 210GPa to 190GPa due to introducing the LL effect.

- Point 4: Defines the third segment, which joins Points 2 and reaches Point 4 with a slope equal to $15 \%$ of the initial slope $\left(0.15 \cdot E^{\prime} \mathrm{A} / \mathrm{L}\right)$. Point 4 is determined by the effective maximum LL plastic displacement, which is the result of reducing maximum plastic displacement by $0.5 \mathrm{~mm}$.

- Point 1: In the first segment with a load equal to the LL's limit load reduced by a factor of $1.1\left(\mathrm{q}_{\mathrm{y}} / 1.1\right)$.

- Point 3: The slope in the second segment is the mean of those of the first and third segments i.e. equal to $57.5 \%$ of the initial slope $\left(0.575 \cdot \mathrm{E}^{\prime} \mathrm{A} / \mathrm{L}\right)$. Point 3 is the result of the intersection of the second and third segments after applying these conditions.

- Point 5: Represents the shore's ultimate load $\left(\mathrm{q}_{\mathrm{u}}\right)$ and is the result of applying this condition and equalizing the slope of the fourth segment to the initial slope.

Curve 1-3-4-5 is therefore a simplified practical definition of the behaviour of the shore-LL unit which has been verified by multiple experimental tests and can thus safely be used to design shoring systems.

\section{Conclusions}

This paper describes the design, production, experimental testing and numerical simulation of a novel mechanical device for applications in the civil engineering field and of special interest in structural engineering. After the first concepts, the final design was obtained with the help of numerical simulations and the DOE technique. The definitive designs (confined LL and LL with tie rods) were turned into different lots of LLs which after testing provided the following conclusions:

- The confined LLs were discarded after the first round of tests as the results showed wide variations, mainly due to partial slippage of the LLs on the rings under different confinement conditions. 
- The LLs with tie rods complied with the desired requirements:

○ They can easily be adjusted and modified to fit any type of shore.

- Initial stiffness is practically the same as the shore in the elastic behaviour.

- At the limit load LLs show plastic behaviour, during which they maintain this load at slightly higher values.

- Their maximum plastic displacement limits the vertical displacement of the structural element they support, e.g. slabs.

- After reaching maximum plastic displacement they can make use of the shore's resistance up to its ultimate load.

- The 190 consecutive repetitive loading tests showed that they can be used repeatedly, although it is recommended to replace them after passing half their maximum plastic displacement.

The identical results obtained between experimental tests and numerical simulations validated the numerical models and showed that the latter can be used to accurately predict LL behaviour in different situations. Finally, a simplified generic method was proposed to establish the behaviour of the shore-LL unit that could also be used e.g. for macro-scale numerical simulations.

To summarise, the paper has shown that the combination of the two fields of civil and mechanical engineering has produced a ground-breaking device that will clearly improve the safety and reduce the cost of building reinforced concrete structures.

\section{Acknowledgements}

The authors would like to express their gratitude to the Spanish Ministry of Education, Culture and Sport for funding received under the FPU Program [FPU13/02466], also to the Generalitat Valenciana [GV/2015/063] and to Professor Salvador Ivorra of Alicante University for helping us to carry out the steel characterization tests. 


\section{References}

[1] Grundy P, Kabaila A. Construction Loads on Slabs with Shored Formwork in Multistory Buildings. J Proc 1963;60:1729-1738.

[2] Duan MZ, Chen WF. Improved simplified method for slab and shore load analysis during construction. Proj Rep CE-STR-95-21 1995.

[3] Fang DP, Geng CD, Zhu HY, Liu X La. Floor load distribution in reinforced concrete buildings during construction. ACI Struct J 2001;98:149-156.

[4] Huang K, Liu X. Effects of temperature variations on safety of reinforced concrete structures during construction. J Shanghai Jiaotong Univ 2014;19:139-145. doi:10.1007/s12204-0141482-x.

[5] Simavorian D, De Brito J, Castro L, Azenha M. Analysis of the effect of shoring on the behaviour of reinforced concrete slabs. Constr Build Mater 2017;143:473-489. doi:10.1016/j.conbuildmat.2017.03.096.

[6] Kaminetzky D. Structural Failures and How to Prevent Them. Civ Eng 1976;46:60-73.

[7] Hadipriono FC, Wang H-K. Causes of falsework collapses during construction. Struct Saf 1987;4:179-195. doi:10.1016/0167-4730(87)90012-9.

[8] Epaarachchi DC, Stewart MG, Rosowsky D V. Structural Reliability of Multistory Buildings during Construction. J Struct Eng 2002;128:205-213. doi:10.1061/(ASCE)07339445(2002)128:2(205).

[9] Buitrago M, Moragues JJ, Calderón PA, Adam JM. Structural failures in cast-in-place RC building structures under construction. In: Makhlouf ASH, Aliofkhazraei M, editors. Handb. Mater. Fail. Anal. with Case Stud. from Constr. Ind. 1st ed, Butterworth-Heinemann, Elsevier; 2018. doi:10.1016/ B978-0-08-101928-3.00008-2.

[10] Buitrago M, Sagaseta J, Adam JM. Effects of sudden failure of shoring elements in concrete building structures under construction. Eng Struct 2018.

[11] Buitrago M, Adam JM, Calderón PA, Moragues JJ. Modelling of RC structures during construction. In: Barros H, Ferreira C, Adam JM, Delatte N, editors. 2nd Int. Conf. Recent Adv. Nonlinear Model. - Des. Rehabil. Struct., Coimbra: 2017, p. 53-62.

[12] Buitrago M, Alvarado YA, Adam JM, Calderón PC, Gasch I, Moragues JJ. Improving construction processes of concrete building structures using load limiters on shores. Eng Struct 2015;100:104-115. doi:10.1016/j.engstruct.2015.06.007.

[13] Alvarado YA. Estudio experimental y numérico de la construcción de forjados hormigonados in situ mediante procesos de cimbrado, clareado y descimbrado de plantas consecutivas. PhD Thesis - Universitat Politècnica de València. [In Spanish], 2009.

[14] ANSYS 15.0. Theory reference. ANSYS Inc. 2014.

[15] Kernes RG, Edwards JR, Dersch MS, Lange DA, Barkan CPL. Investigation of the Dynamic Frictional Properties of a Concrete Crosstie Rail Seat and Pad and its Effect on Rail Seat Deterioration (RSD). Transp. Res. Board 91st Annu. Meet., Illinois: Railtec; 2011, p. 1-14.

[16] Gorst JS, Williamson SJ, Pallett PF, Clark LA. Research Report 071: Friction in temporary works. Birmingham: 2003.

[17] Navarro-Manso A, Del Coz Díaz JJ, Alonso-Martínez M, Castro-Fresno D, Alvarez Rabanal FP. Patch loading in slender and high depth steel panels: FEM-DOE analyses and bridge launching application. Eng Struct 2015;83:74-85. doi:10.1016/j.engstruct.2014.10.051.

[18] Del Coz Diaz JJ, Garcia-Nieto PJ, Alvarez-Rabanall FP, Alonso-Martínez M, DominguezHernandez J, Perez-Bella JM. The use of response surface methodology to improve the thermal transmittance of lightweight concrete hollow bricks by FEM. Constr Build Mater 2014;52:331- 
344. doi:10.1016/j.conbuildmat.2013.11.056.

[19] Del Coz Díaz JJ, Nieto PJG, Lozano Martínez-Luengas A, Suarez Domínguez FJ, Domínguez Hernández J. Non-linear numerical analysis of plywood board timber connections by DOE-FEM and full-scale experimental validation. Eng Struct 2013;49:76-90. doi:10.1016/j.engstruct.2012.11.003.

[20] Del Coz Díaz J, Serrano López M, López-Colina Pérez C, Álvarez Rabanal F. Effect of the vent hole geometry and welding on the static strength of galvanized RHS K-joints by FEM and DOE. Eng Struct 2012;41:218-233. doi:10.1016/j.engstruct.2012.03.050.

[21] Del Coz Díaz JJ, García Nieto PJ, Álvarez Rabanal FP, Lozano Martínez-Luengas A. Design and shape optimization of a new type of hollow concrete masonry block using the finite element method. Eng Struct 2011;33:1-9. doi:10.1016/j.engstruct.2010.09.012.

[22] Castro-Fresno D, Del Coz Díaz JJ, Alonso Martínez M, Blanco-Fernandez E, Polanco Madrazo JA. Numerical and experimental study of a new type of clip for joining cables. Eng Struct 2012;44:107-121. doi:10.1016/j.engstruct.2012.05.048.

[23] Statgraphics. Statgraphics Centurion XVI. StatPoint Technologies, Inc. 2013.

[24] Alvarado YA, Calderón PA, Adam JM, Payá-Zaforteza IJ, Pellicer TM, Pallarés FJ, et al. An experimental study into the evolution of loads on shores and slabs during construction of multistory buildings using partial striking. Eng Struct 2009;31:2132-2140. doi:10.1016/j.engstruct.2009.03.021.

[25] Gasch I, Alvarado YA, Calderón PA, Ivorra S. Construction loads using a shoring-clearingstriking process. Proc Inst Civ Eng - Struct Build 2015;167:217-229. doi:10.1680/stbu.12.00006.

[26] EN 1065. Adjustable telescopic steel props. Product specifications, design and assessment by calculation and tests 1998.

[27] EN ISO 6892-1. Metallic materials. Tensile testing. Part 1: Method of test at room temperature 2009. 


\section{Figure captions:}

- Fig. 1. Sketch of the shoring system and detail of a shore.

- Fig. 2. Theoretical behaviour of load limiters.

- Fig. 3. Stages of the LL design: a) location of LL, b) conceptual design, c) first approach, d) second approach and e) final approach.

- Fig. 4. Different solutions for the design: a) LL with tie rods, b) confined LL and c) stamped ring.

- Fig. 5. Design curves for the solutions: (a) load limiters with $3 \mathrm{~mm}$ tie rods and (b) confined load limiters with $2 \mathrm{~mm}$ height.

- Fig. 6. Production of LL: a) manufacturing process, b) LL with tie rods and c) confined LL.

- Fig. 7. Tests setups.

- Fig. 8. Tests of LLs on shores and isolated LLs.

- $\quad$ Fig. 9. Steel characterization test setup.

- Fig. 10. Tests on shores for LLs with tie rods (L01-A1, L01-A2) and confined LLs (L01B1, L01-B2).

- Fig. 11. Tests of isolated LLs with tie rods (L01-A3 and L01-A4) and isolated confined LLs (L01-B3 and L01-B4).

- Fig. 12. (a) Steel characterization and (b) tests of LLs on shores (L02-AL1-7, L02-AL1$8)$.

- Fig. 13. (a) Tests of isolated LLs (L02-AL1-1, L02-AL1-2) and (b) points on the loaddisplacement curve for the definition of the cyclic tests.

- Fig. 14. Results of tests of isolated LLs with cyclic loading: (a) L02-AL1-3, (b) L02AL1-4, (c) L02-AL1-5, and (d) L02-AL1-6.

- Fig. 15. (a) Comparison between simulated and experimental results and (b) simplified LL on shore behaviour for macro-scale models. 